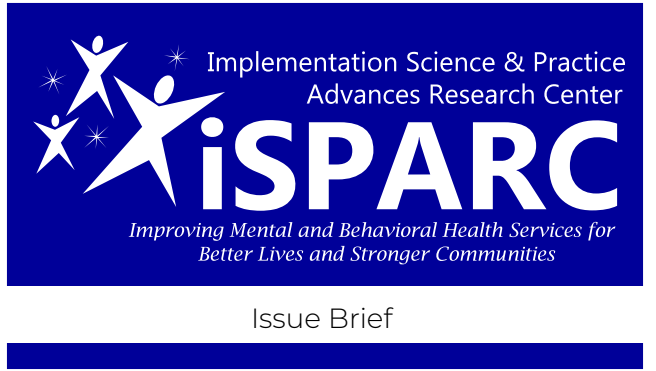

Vol 18 Issue 3

\title{
BRAIN INJURY CLUBHOUSES
}

Author Information: Colleen McKay, MA, CAGS ${ }^{a}$, Jason Young, MSW ${ }^{b}$, \& Cindi Johnson, MA, CBIST ${ }^{c}$, Ronald T. Seel, PhD ${ }^{d}$ aProgram for Clubhouse Research, Department of Psychiatry, University of Massachusetts Medical School, Worcester, Massachusetts, USA; ${ }^{b}$ Community Brain Injury Services, Richmond, Virginia, USA; ' ${ }^{2}$ Side by Side Brain Injury Clubhouse, Stone Mountain, Georgia, USA; 'Center for Rehabilitation Science and Engineering (CERSE), Virginia Commonwealth University, Richmond, Virginia, USA.

The National Institutes of Health (NIH) reported that the number of people living with permanent disability from brain injury grows annually as medical technology has advanced in life saving techniques. However, community-based programs which enable brain injury survivors to live productive lives throughout the entire course of recovery have not grown proportionately to meet this the need. Brain Injury Clubhouses were developed to address the need for coordinated, long-term, community-based supports for brain survivors in a community-based setting. Brain Injury Clubhouses are designed to improve the lives of persons with $\mathrm{ABI}$ and reduce strain on caregivers and healthcare services

The information below is designed to provide funders, administrators, policy makers, and other stakeholders with an overview of Brain Injury Clubhouses. The brief also provides outcomes associated with participation in a Brain Injury Clubhouse from a recent research study to provide stakeholders with a better understanding of Brain Injury Clubhouses.

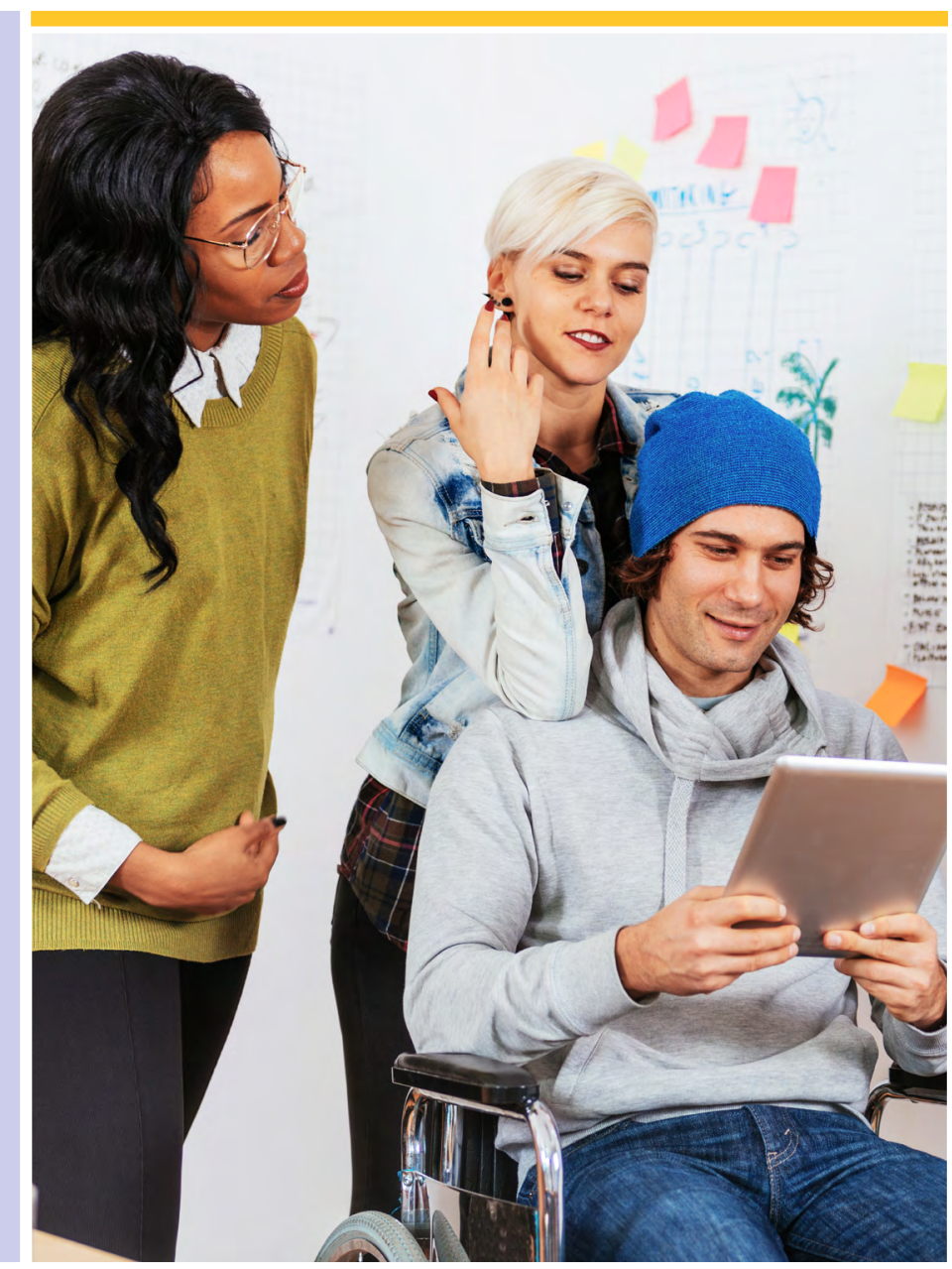

\section{Brain Injuries}

Acquired brain trauma is the second most prevalent disability in the U.S., affecting 13.5 million Americans ${ }^{1}$. Impacts of brain injuries may be short term or affect survivors for the rest of their lives. Chronic health problems and cognitive, physical, emotion$\mathrm{al}$, and/or behavioral changes can result from moderate or severe brain injuries ${ }^{2}$. Brain injury sur- vivors may experience limitations in meaningful activities such as vocational functioning or employment $^{3}$ or be at risk for unintentional injury, harm, or victimization ${ }^{4-5}$. A brain injury may impact self-identity, community reintegration, social networks or quality of life ${ }^{6-8}$. These issues can have lasting effects on the individuals experiencing a brain injury and their families. Thus, there is a need for effective community services that reduce the problems associated with brain injuries. Acquired brain injury (ABI) clubhouses are a long-term, person-centered, service delivery model designed to improve the lives of persons with $\mathrm{ABI}$ and reduce burden on caregivers and healthcare services. 


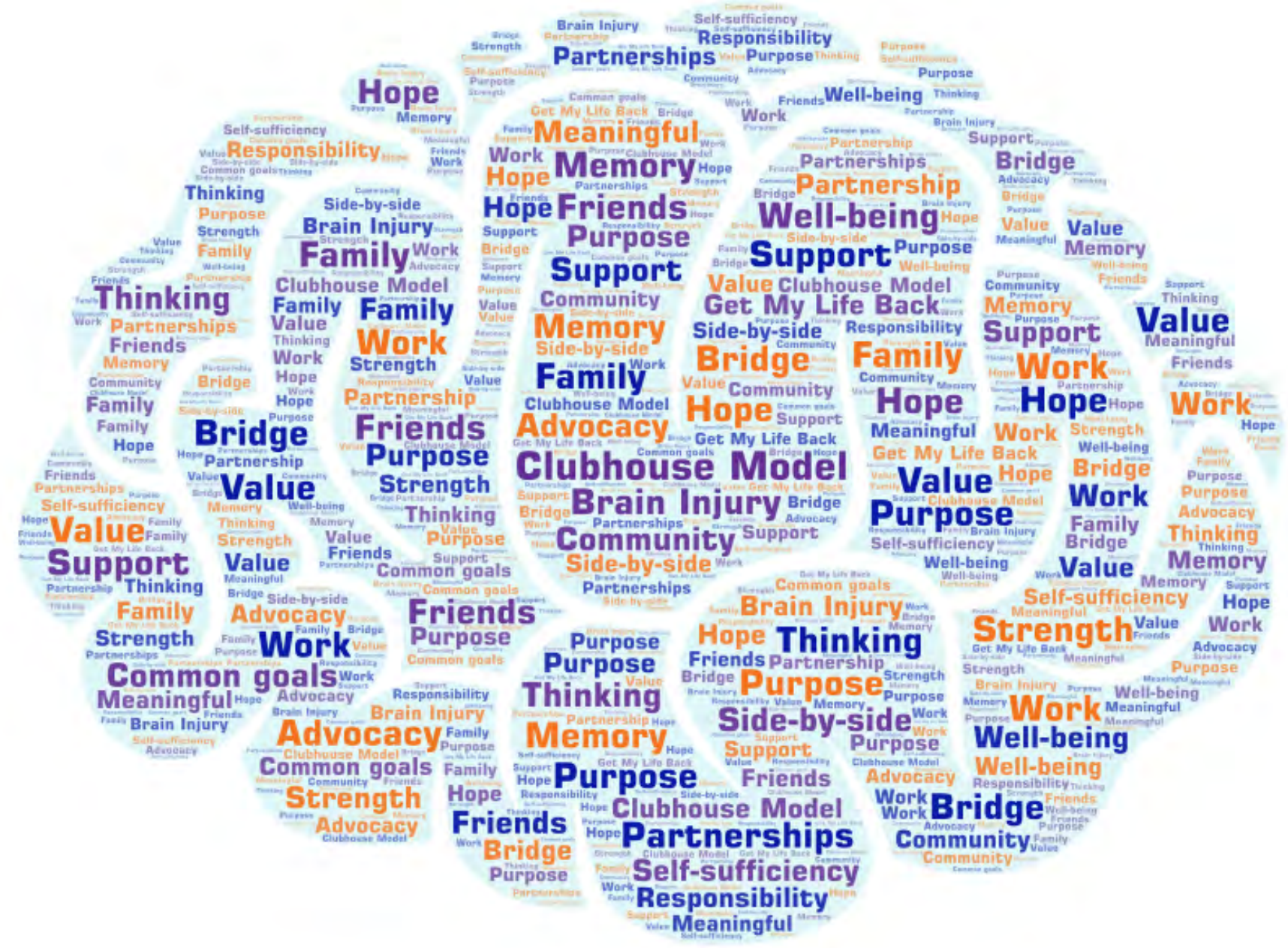

\section{What are Brain Injury Clubhouses?}

Brain injury clubhouses originated with the inception of Fountain House in New York City in 1948. The initial goal of the clubhouse was to provide a restorative environment to address social isolation by offering support for people living with mental illness. Today over three hundred mental health clubhouses affiliated with Clubhouse International (https:// clubhouse-intl.org) are located in thirty countries.

Clubhouse participants are referred to as members rather than patients or clients9. Clubhouse membership is voluntary and without time limits. Each member can enter, leave, and re-enter the clubhouse as needed. Members are wanted, needed and expected and each member's involvement is an important contribution to the clubhouse community.

Mental health clubhouses follow a set of International Clubhouse Standards that serve as a bill of member rights and provide clubhouses with operational guidelines in eight domains:

1) Membership,

2) Space,

3) Relationships,

4) the Work-Ordered Day (WOD),

5) Employment,

6) Education,

7) Functions of the House, and

8) Funding, Governance and Administration.
The clubhouse provides members with opportunities for meaningful relationships, education, employment, securing housing, and evening, weekend, and holiday activities. These activities occur in a rehabilitative environment known as the Work Ordered Day $(\mathrm{WOD})^{10}$. The WOD parallels a typical business day and provides opportunities for members to work side-by-side with clubhouse staff and other members. to complete all aspects of clubhouse operations including decision-making and governance. Evidence from research supports the efficacy of the Brain Injury Clubhouses in helping members obtain employment or education, reducing hospitalization(s) and improving quality of life $^{11}$. 


\section{Acquired Brain Injury (ABI) Clubhouses}

Acquired brain injury (ABI) clubhouses are supportive community centers modeled after mental health clubhouses that offer people living with brain injury opportunities to resume productive lives through partnership, work, and social connections. Brain injury lubhouses serve adults with acquired and traumatic brain injuries. As with mental health clubhouses, each member of a brain injury clubhouse is recognized for their own goals and abilities. Every member is considered a critical part of the ABI clubhouse community.

Clubhouses help members take ownership of their own recovery so they can lead satisfying, productive lives ${ }^{12}$. Clubhouses address many social determinants of health including improving social networks, peer relationships, recreation, unemployment and work, social supports, food security, and transportation. Brain Injury Clubhouses offer a supportive environment where members can regain lost skills, find competitive employment, education, and develop meaningful relationships. Brain injury clubhouses provide a variety of services and supports including but not limited to outreach, family supports, wellness and health promotion activities, linkages to health care, help with entitlements, and social supports or recreational activities.

The first brain injury clubhouse was attempted in the late 1980 's ${ }^{13}$. Within several years brain injury clubhouses were operational in three states ${ }^{13}$. Today, there are

Table 1. Clubhouse Characteristics

\begin{tabular}{|l|c|c|}
\hline Characteristic & Mean & Range \\
\hline Length of Operation as a Clubhouse (Years) & 16.2 & $11.2-20.9$ \\
\hline Clubhouse has an Auspice (Parent Agency) & $87.50 \%$ & $0-100 \%$ \\
\hline CARF Accreditation & $87.50 \%$ & $0-100 \%$ \\
\hline Attempts to Meet all IBICA Standards & $100 \%$ & $100 \%-100 \%$ \\
\hline Annual Budget & $\$ 472,237$ & $\$ 199,871-$ \\
& & $\$ 461,643$ \\
\hline Cost per Year per Person' & $\$ 9,873.62$ & $\$ 5125-\$ 21,983$ \\
\hline Cost per Day per Person' & $\$ 86.43$ & $\$ 33-\$ 158$ \\
\hline \# Full-Time Staff (FTE's) & 5.25 & $3-10$ \\
\hline Ratio of Active Members per FTE Staff & $9.3: 1$ & $6: 1-13: 1$ \\
\hline 1. Cost calculations are intended to provide descriptive costs about clubhouses and are not intended for rate \\
setting purposes.
\end{tabular}

Table 2. Funding Source(s)

\begin{tabular}{|l|c|c|}
\hline Funding Type & Mean & Range \\
\hline State and Local Government & $69.5 \%$ & $6.6 \%-100 \%$ \\
\hline $\begin{array}{l}\text { Fee for Service- Public } \\
\text { (VR and Medicaid Waiver) }\end{array}$ & $11.0 \%$ & $0 \%-48.1 \%$ \\
\hline $\begin{array}{l}\text { Fee for Service- Private } \\
\text { (Work Comp, Private Pay, Group Health, other) }\end{array}$ & $1.8 \%$ & $0 \%-5 \%$ \\
\hline $\begin{array}{l}\text { Charitable Gifts, Grants, Donations, Fundraising } \\
\text { Events }\end{array}$ & $17.7 \%$ & $0 \%-45.3 \%$ \\
\hline
\end{tabular}

brain injury clubhouses in at least ten states. Seventeen brain injury clubhouses throughout the United States and Canada network through the International Brain Injury Clubhouse Alliance (brain injuryclubhouses.net/).

IBICA was founded in 2005 to support the development, training, quality, and stability of brain injury clubhouses. IBICA developed a set of consensus ABI Clubhouse Standards for ABI clubhouses $^{14}$ that parallel the International Clubhouse Standards for mental health clubhouses. Most brain injury clubhouses are accredited by CARF International, an independent, non-profit, and an international accreditor of health and human services.

\section{Research on Brain Injury Clubhouses}

Findings from a multi-site longitudinal study of brain injury clubhouses provides additional information including key ingredients of these programs and outcomes associated with participation in them. Eight brain injury clubhouses affiliated with IBICA in four states completed an electronic survey-the Brain Injury Clubhouse Profile Questionnaire (CPQ) in 2019 as part of the larger research project. The CPQ gathers program-level information concerning practices, characteristics, concerns, and performance outcomes of club- 
house programs. CPQ data below provides information about the brain injury Clubhouses including members served, infrastructure, staffing, programming, and other organizational characteristics.

\section{Organizational Characteristics of Brain Injury Clubhouses $(\mathbf{n}=\mathbf{8})$}

Funding mechanisms for brain injury clubhouses vary from state to state. The five clubhouses in Virginia receive most of their funding from the state. Less than ten percent of funding for these clubhouses is through Medicaid. TBI waivers in Georgia and Pennsylvania allow Medicaid funds to be used for community-based programs like brain injury clubhouses. Yet, funding mechanisms like a national brain injury waiver for participation in ABI clubhouses have not been established. The variations in number of individuals served, number of staff, the extent of services offered, and hours of operation may be reflected by differences in funding across states.

\section{ABI Clubhouse Memberships}

" Most ABI clubhouse members $(69 \%)$ are between the ages of thirty and sixty.

»Approximately sixty-seven percent of ABI clubhouse members are male.

» Most members are Caucasian $(61.5 \%)$ or African American (28\%).

» Member's primary diagnosis is a TBI $(59 \%)$ or a non-TBI $(41 \%)$.

$»$ Primary causes of injury include a vehicle accident $(38.4 \%)$, or a stroke $(20.4 \%)$.

¿ Less than three percent of active members in brain injury

Table 3. Membership and Member Participation

\begin{tabular}{|l|c|c|}
\hline Characteristics & Mean & Range \\
\hline Number of Referrals Annually & 32 & $10-90$ \\
\hline Average Daily Attendance & 16.8 & $8-29$ \\
\hline Evening Weekend Participation & 11.8 & $0-28$ \\
\hline Active Membership & 44.9 & $21-60$ \\
\hline $\begin{array}{l}\text { Total Clubhouse Membership (Lifetime of Club- } \\
\text { house) }\end{array}$ & 267.4 & $50-615$ \\
\hline
\end{tabular}

Table 4. Health Impacts for Persons with $A B I$ Participating in $A B I$ Clubhouses

\begin{tabular}{|l|c|c|}
\hline Health Impact(s) & Change & Significance \\
\hline Number of hospitalization risk factors & Reduced & $<.01$ \\
\hline Depressive symptoms & Reduced & $<.05$ \\
\hline General health & Improved & $<.05$ \\
\hline Impact of poor health on daily activities & Reduced & $<.01$ \\
\hline Abilities (attention, memory) & Improved & $<.01$ \\
\hline Participation (initiation, activities, social) & Improved & $<.01$ \\
\hline
\end{tabular}

clubhouses experienced the brain injury within the past year.

» The length of time post injury is

$1-5$ years $(23.4 \%), 6-10$ years

$(21.5 \%), 11-20$ years $(22.7 \%)$

or more than twenty years $(29.9 \%)$.

» Many members also have co-morbid mental health conditions $(54.9 \%)$.

\section{ABI Clubhouse Impacts}

Data from the longitudinal study also examined health impacts for persons with ABI $(n=49)$ who participated in brain injury clubhouses. Results showed statistically significant positive impacts including neurobehavioral, safety, physical and mental health, and functional ability. Many of these individuals also had a variety of co-morbid health conditions including but not limited to depression $(45 \%)$, seizure disor$\operatorname{der}(\mathrm{s})(29 \%)$, sleep-wake disorders (sleep apnea, insomnia, oth- er) $(18 \%)$, tone/spasticity $(18 \%)$, or other disorders $(33 \%)$.

ABI clubhouse members showed improved safety-related behavior and reduced safety risk on twelve behaviors/activities after participating in the clubhouse for six months. Improvements that were found in carrying out everyday activities, judgment and following recommendations may lead to real changes such as reduced injuries, need for healthcare services, and professional or family caregiver supervision.

ABI clubhouse members had reductions in:

» The number of days that poor health restricted their activities Hospitalization risk factors Actual emergency room visits Acute hospitalizations

These reductions represent savings in hospitalization costs and follow-up care. While these 


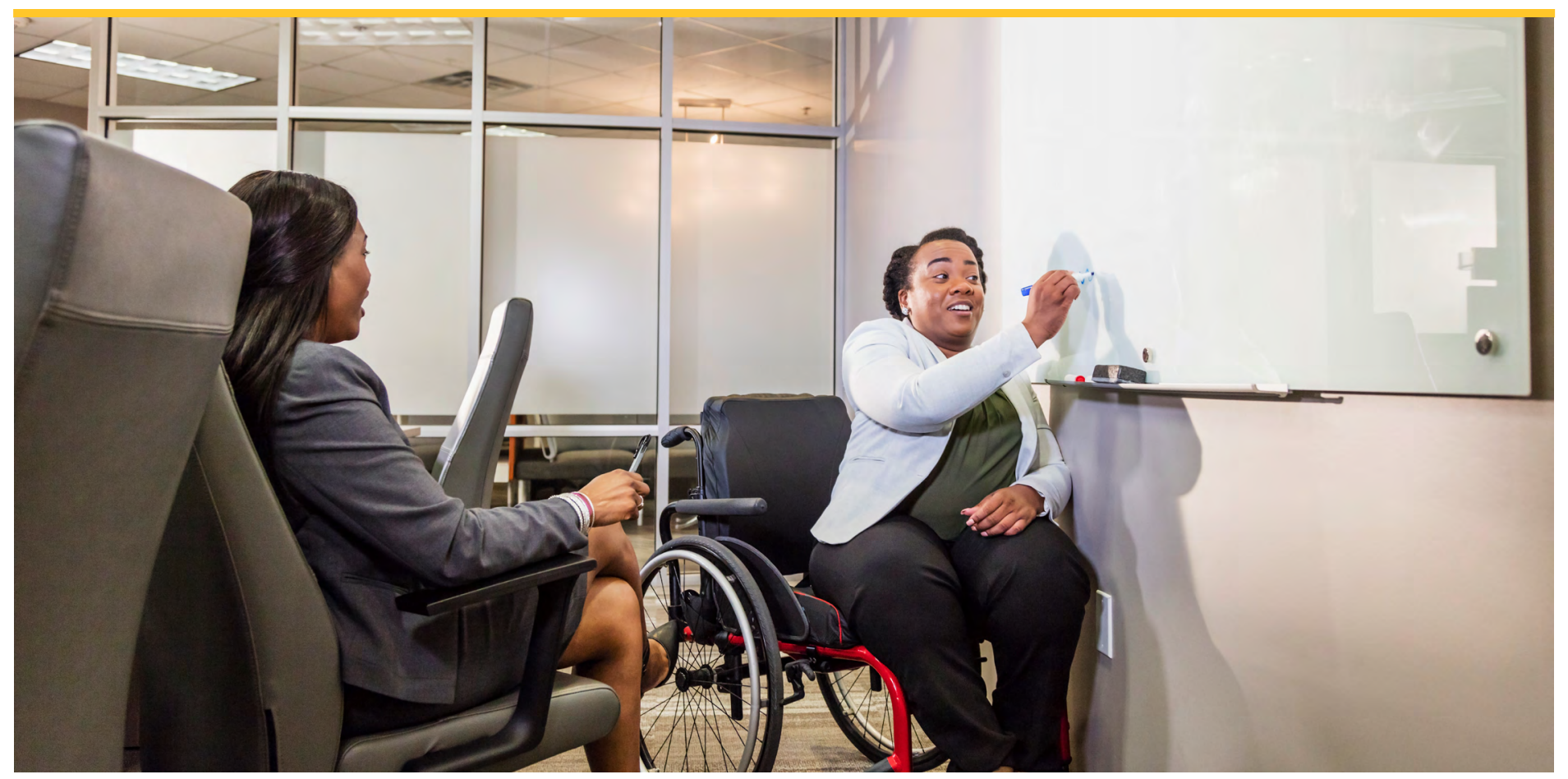

positive impacts were not seen in every person in our study, the benefits of clubhouse participation on daily life and functional abilities of a person living with a brain injury cannot be understated.

Additional research is needed that identifies and describes the full impact of the array of services available within brain injury clubhouses. Studies are needed that examine the cost-effectiveness of brain injury clubhouses and/or the impact of:

»Specific clubhouse services and supports on outcomes

»Clubhouse participation on family caregiver burden

»Clubhouse quality assurance efforts

»Clubhouse participation on member health and participation including return to work
Findings from these studies would be beneficial to funders, administrators, service providers, researchers, and other stakeholders, particularly in an era of limited funding.

\section{Conclusion}

ABI clubhouses can provide an option to address the rising impact of brain injuries and the lack of community-based services to address them. The ABI clubhouses in this study reported offering a wide array of services and supports to assist members. The ABI Clubhouses provides services and supports to those with severe disability and initial evidence shows reduced emergency medical utilization and risk factors, and improved safety, community independence and health-related life quality.

\section{References}

1. Schiller JS, Lucas JW, Ward BW, Peregoy JA. Summary health statistics for U.S. adults: National Health Interview Survey, 2010. Vital Health Stat
10. 2012(252):1-207. Epub 2012/07/28. PubMed PMID: 22834228.

2. Centers for Disease Control. Moderate to Severe Traumatic Brain Injury is a Lifelong Condition. Retrieved January 11, 2021 from: https:/www. cdc.gov/traumaticbraininjury/ pdf/Moderate to Severe TBI Lifelong-a.pdf

3. Tate RL, Strettles B, Osoteo T. Enhancing Outcomes After Traumatic Brain Injury: A Social Rehabilitation Approach. In: Wilson B, editor. Neuropsychological Rehabilitation Theory and Practice. Lisse, The Netherlands: Swets \& Zeitlinger, B.V.; 2003. p. 137 69.

4. Kreutzer JS, Livingston LA, Everley RS, Gary KW, ArangoLasprilla JC, Powell VD, et al. Caregivers' concerns about judgment and safety of patients with brain injury: a preliminary investigation. PM\&R. 2009;1(8):723-8. https://doi.org/10.1016/j. 
pmrj.2009.07.005

5. Tyson BT, Pham MT, Brown NT, Mayer TR. Patient safety considerations in the rehabilitation of the individual with cognitive impairment. Physical Medicine and Rehabilitation Clinics. 2012;23(2):315-34. https://doi. org/10.1016/j.pmr.2012.02.007

6. Fleming J, Braithwaite $\mathrm{H}$, Gustafsson L, Griffin J, Collier AM, Fletcher S. Participation in leisure activities during brain injury rehabilitation. Brain Injury. 2011;25(9):806-18. doi :10.3109/02699052.2011.585 508 .

7. Corrigan JD, Cuthbert JP, Harrison-Felix C, Whiteneck GG, Bell JM, Miller AC, et al. US Population Estimates of Health and Social Outcomes 5 Years After Rehabilitation for Traumatic Brain Injury. The Journal of Head Trauma Rehabilitation. 2014;29(6):E1-
E9. doi: $10.1097 /$

htr.0000000000000020.

PubMed PMID: 00001199-

201411000-00010.

8. Hanson A, Dillahunt-Aspillaga

C. Traumatic Brain Injury

Clubhouses: A Community

Reintegration Paradigm. 2016.

9. Doyle A, Lanoil J, Dudek KJ.

Fountain House: Creating community in mental health practice. New York, New York: Columbia University Press; 2013. https://doi.org/10.7312/ doyl15710

10. Jackson RL. The clubhouse model: Empowering applications of theory to generalist practice. 1 st ed. Belmont, CA: Wadsworth.; 2001.

11. McKay CE, Nugent KL, Johnsen M, Eaton WW, \& Lidz CW. Examining the Evidence for the Clubhouse Model: A Systematic Review.
Administration and Policy in Mental Health and Mental Health Services Research. 2018;45(1): 28-47. doi:10.1007/s10488-016-07603

12. Adkins V, Lenyoun M. An active treatment alternative: $\mathrm{A}$ clubhouse model. The Journal of Cognitive Rehabilitation. 2004;22(2):22-6.

13. Farmer S. Spotlight on the safety net: Traumatic brain injury clubhouses in North Carolina. North Carolina Medical Journal. 2015;76(2):123-4. https://doi. org/10.18043/ncm.76.2.123

14. Volpe R. Casebook of Exemplary Evidence-Informed Programs that Foster Community Participation After Acquired Brain Injury.: Ontario Neurotrauma Foundation. 2012.

\section{Suggested Citation:}

McKay C., Young J., Johnson C., Steel R.T. Brain Injury Clubhouses. Psychiatry Information in Brief 2021;18(1).

This research is supported by Project \#: A262-76758 from the Virginia Commonwealth Neurotrauma Initiative (CNI) Trust Fund and managed by the Virginia Department for Aging and Rehabilitative Services (DARS). The contents are the sole responsibility of the authors and do not necessarily represent the official views of CNI Trust Fund or DARS.

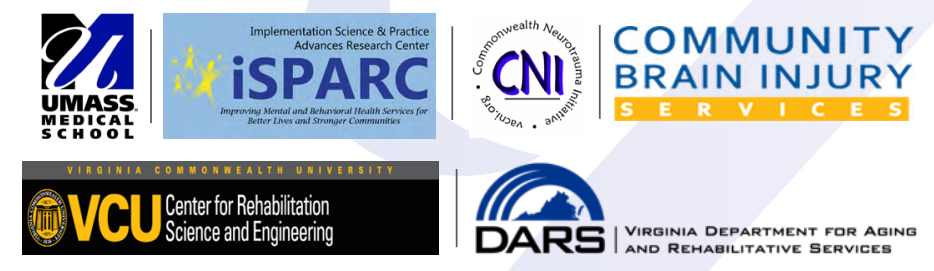

